\title{
FLEXURAL IMPROVEMENT OF PLAIN CONCRETE BEAMS STRENGTHENED WITH HIGH PERFORMANCE FIBRE REINFORCED CONCRETE
}

\author{
M. N. Isa* \\ DEPARTMEnt OF Civil ENGineERING, BAyERo University Kano, Kano State, NIGERIA \\ Email address: mnisheshe@gmail.com
}

\begin{abstract}
Strengthening of concrete structures have become inevitable due to unavoidable factors such as fatigue and aggressive environmental conditions causing deterioration of concrete structures. Many researchers have turned in the direction of using various high strength and high performance concretes due to their high structural and durability properties, for the purpose of repair and strengthening of concrete structures against these aggressive conditions. As a result, this study carryout experimental, numerical and analytical investigation to study the behaviour of plain concrete (PC) beams strengthened with High Performance Fibre Reinforced Concrete (HPFRC) layer using three different jacketing configurations and tested in flexure. Results show significant improvement in both stiffness and load bearing capacity of plain concrete beams.
\end{abstract}

Keywords: High performance fibre reinforced concrete (HPRC), Plain concrete, Strengthening configuration, Finite element model, Analytical model

\section{INTRODUCTION}

Concrete structures are subjected to various types of stresses and moments in the form of flexure, shear or torsion. These stresses and moments in addition to material defects, human errors and environmental conditions cause degradation of concrete structures. When concrete structures are damaged, they can either be demolished and reconstructed or repaired and strengthened provided after strengthening, the structure will be able to perform optimally under service. Because of the shortcomings of conventional concrete members especially in highly loaded conditions and susceptibility to corrosion, a lot of researches have been carried on ways to strengthen the conventional concrete members. Various methods have been developed to increase their strength capacity by using Carbon Fibre Reinforced Polymer (CFRP) and steel plate. However, strengthening using FRP or steel plates does not come cheap because of the high cost of material and application and the fact that FRP does not prevent corrosion in a structural member. Attention is now being given on using high strength concretes in strengthening conventional concrete members. Experimental study on composite beams having a layer of ultra-high performance fibre reinforced concrete (UHPFRC) in tension and either normal strength or high strength concrete (NSC or HSC) in compression was carried out. The results demonstrated improvement in both flexural and shear capacity of the composite systems [1]. The possibility of using UHPFRC to strengthen existing reinforced concrete (RC) structures was investigated by conducting experimental sand analytical study on 12 full-sized RC beams with the UHPFRC layer in tension. The results show significant increases in ultimate load and stiffness of the beams [2]. Experimentally and numerically investigation on the behaviour of full-scale RC beam strengthened with a jacket of Fibre Reinforced Concrete (FRC) having a tensile hardening behaviour shows significant enhancement in capacity both at ultimate and serviceability limit states [3]. The flexural behaviour of RC beams damaged up to 80 and $90 \%$ of the failure capacity of the beams and repaired with overlay of UHPFRC was investigated [4]. The results indicated that adding UHPFRC overlay on the tension face of damaged RC beam increases both load capacity and ductility. Experimental and numerical study on the use of UHPFRC to strengthen $\mathrm{RC}$ beam at different locations shows promising improvement in capacity [5]. Damaged RC beams repaired with a fibre reinforced concrete known as CARDIFRC using various strengthening configurations, shows that the beams could be successfully strengthened by using this material and strengthening technique [6]. A series of experimental studies conducted on composite beams in which RC beams were strengthened with thick 
element of steel reinforced UHPFRC (R-UHPFRC) as additional tensile reinforcement. Results show significant improvement in the failure load of the beams by 2.0 to 2.8 times higher than the control beams [7]. Investigation on the suitability of UHPFRC to strengthen RC beams under torsion was conducted using experimental and numerical methods. Results of strengthening RC beams with UHPFRC in all four sides enhance the torsional behaviour and increase the capacity of the beams more than using two or three sides only [8].

\section{NEED FOR RESEARCH}

The review of existing literatures carried out showed that all the studies were conducted on strengthening reinforced concrete beams. No studies are found investigating the behaviour of plain concrete beams, which if found suitable can be extended for use in corrosion prone environments and for repairing of corrosion deteriorated RC members. In this study, an experimental, numerical and analytical investigations were conducted to study the flexural behaviour of plain concrete (PC) beams strengthened with (HPFRC) layer using three different jacketing configurations.

\section{EXPERIMENTAL PROGRAMME}

Various experimental studies consisting of material strength and flexural strength test were carried out. Material strength test conducted include the uniaxial stress-strain test in tension and in compression for both concrete and HPFRC samples. The results of the material strength test were utilized to develop the finite element models of the beam specimens as well as their analytical models. The strengthened beam specimens as well as the control were tested in flexure under a four point loading arrangement.

\subsection{Specimen Preparation and Material Properties}

A total of four plain concrete beams were prepared. The beams are of $1400 \mathrm{~mm}$ in length $140 \mathrm{~mm}$ wide and $230 \mathrm{~mm}$ in depth. The average 28-days cylinder compressive strength of the normal concrete and HPFRC are $f_{c}^{\prime}=54 \mathrm{MPa}$ and $132 \mathrm{MPa}$ respectively and an average split tensile strength of $f_{t, s p}^{\prime}=3.16 \mathrm{MPa}$ and $14.21 \mathrm{MPa}$ respectively. Both tests were carried out on $75 \times 150 \mathrm{~mm}$ concrete cylinders in accordance with ASTM C39/C39M-16 and ASTM C496/C496M-11, respectively.

Type I Portland cement, micro-silica, dune sand, steel fibres, water and superplasticizer were used to prepare the HPFRC used in this study. The steel fibres used have a tensile strength of $2500 \mathrm{MPa}$. Uniaxial stress strain results of HPFRC in compression is obtained in accordance with ASTM C469 using HPFRC cylinders, while the uniaxial stress-strain results in tension were obtained by carrying out uniaxial direct tensile strength test on UHPFRC dog-bone specimens.

\subsection{Strengthening schemes}

The concrete beam specimens were strengthened using three different strengthening configurations as shown in Table 1:

Table 1: Strengthening configurations

$\begin{gathered}\text { Strengthening } \\ \text { Configuration (Jacket } \\ \text { Thickness }=30 \mathrm{~mm})\end{gathered}$
$P C-$ Control
$P C-B O T S J$

\subsection{Specimen Preparation}

The surfaces of the beams were sandblasted to an average depth of $2 \mathrm{~mm}$ after 28 days. The beams were strengthened in the laboratory by casting $30 \mathrm{~mm}$ thick fresh HPFRC layer around the sandblasted surfaces of the beams specimens and then moist cured after $24 \mathrm{hrs}$ for 28 days inside curing tanks.

\subsection{Flexural Strength Test}

The flexural strength test set-up is shown in Figure 1. The beams were tested under a four point loading arrangement. Instruments including linear variable transducer (LVDT's) and various strain gauges were used to measure displacements and deformation of the beams specimens respectively.

\section{ANALYSIS AND DISCUSSION OF EXPERIMENTAL RESULTS}

$P C-$ Control failed in a very brittle manner with the development of a single flexural crack at the mid-span which goes directly throughout the entire beam as shown in Figure 2(a). PC - BOT SJ's failure was also brittle with the development of a single flexural crack at a distance $220 \mathrm{~mm}$ to the left of beam mid-span. However, cracking load was much higher than in the case of $P C-$ Control as shown in Figure 2(b). Similarly, for $P C-2 S J$ a single crack was developed at mid-span similar to $P C-$ Control which later deviates into a branching crack around mid-depth of the beam specimen 
indicating a more ductile behaviour as shown in Figure 2(c). In the case of $P C-3 S \mathrm{~J}$, failure is less brittle than the previous mentioned specimens with the development of two flexural cracks at about $120 \mathrm{~mm}$ to the left of the beam mid span (similar to $P C-B o t S J$ ) as shown in Figure 2(d). Properties of the tested beams is as shown in Table 2. It was observed that this strengthening technique increases the cracking load of the beams specimen and decreases brittleness of the beam.

Load-deflection behaviour shown in Figure 3 shows that, $P C-$ Control shows a very brittle collapse once the elastic range of the beam is exceeded (at a very small deflection $<1 \mathrm{~mm}$ ) which splits the beam into two halves. $P C-B O T S J$ shows similar brittle behaviour but with a more elastic response by reaching a higher load capacity and mid-span deflection compared to $P C-$ Control as shown in Figure 3. Despite showing similar brittle failure, $P C-2 S J$ and $P C-3 S J$ however shows considerable amount of softening, and undergoes higher amount of deflection without breakage of the specimens. Properties of tested beams are shown in Table 3.

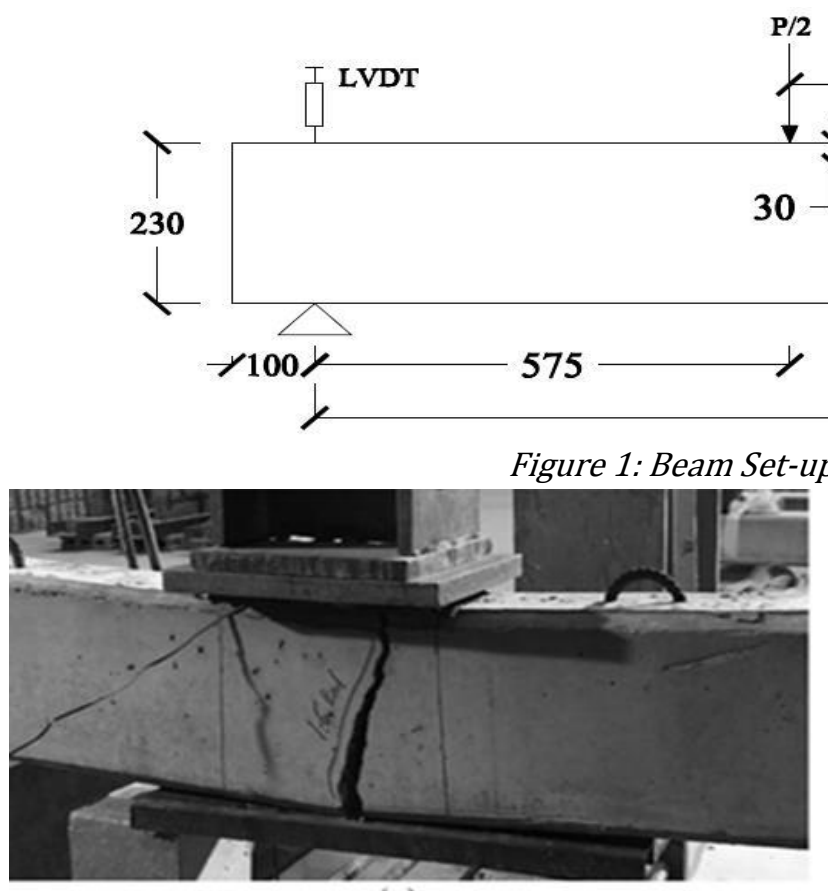

(a)

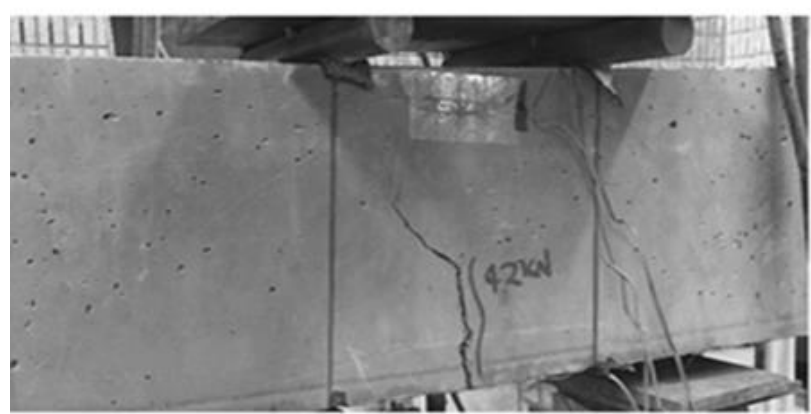

(c)

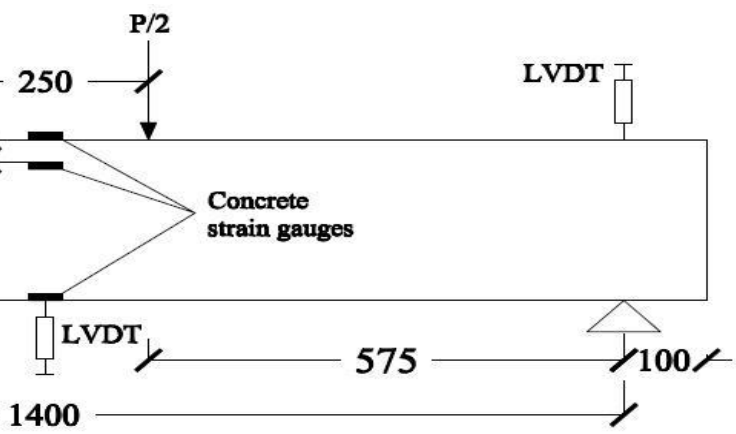

for flexural strength test

(b)

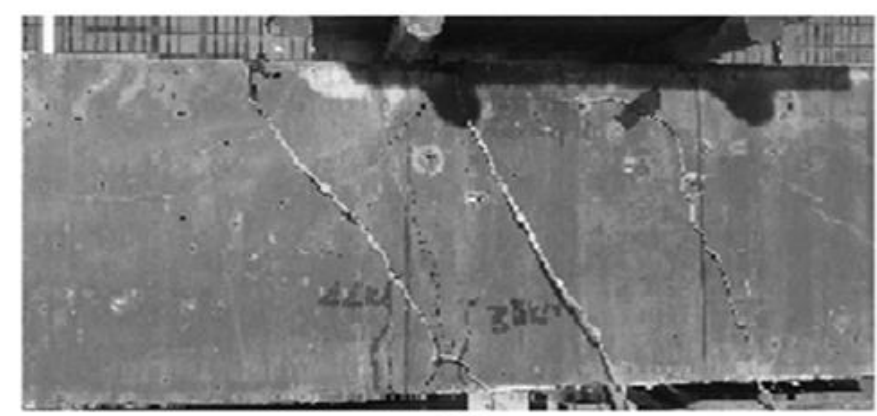

(d)

Figure 2: Crack patterns of specimens (a) PC - Control (b) PC - BOT SJ (c) PC - 2 SJ (d) PC - 3 SJ

Table 2: Cracking properties beam specimens

\begin{tabular}{ccccc}
\hline Specimen & $\begin{array}{c}\text { Cracking } \\
\text { Load (KN) }\end{array}$ & Failure Crack type & $\begin{array}{c}\text { Crack width at } \\
\text { Failure Load (mm) }\end{array}$ & $\begin{array}{c}\text { Crack Width on } \\
\text { unloading (mm) }\end{array}$ \\
\hline$P C-$ Control & 16 & Flexure & Broken & Broken \\
$P C-$ BOT SJ & 30 & Flexure & 2.0 & 0.8 \\
$P C-2 S J$ & 42 & Branching flexure & 4.0 & 2.5 \\
$P C-3 S J$ & 38 & Branching flexure & 1.5 & 1.0 \\
\hline
\end{tabular}




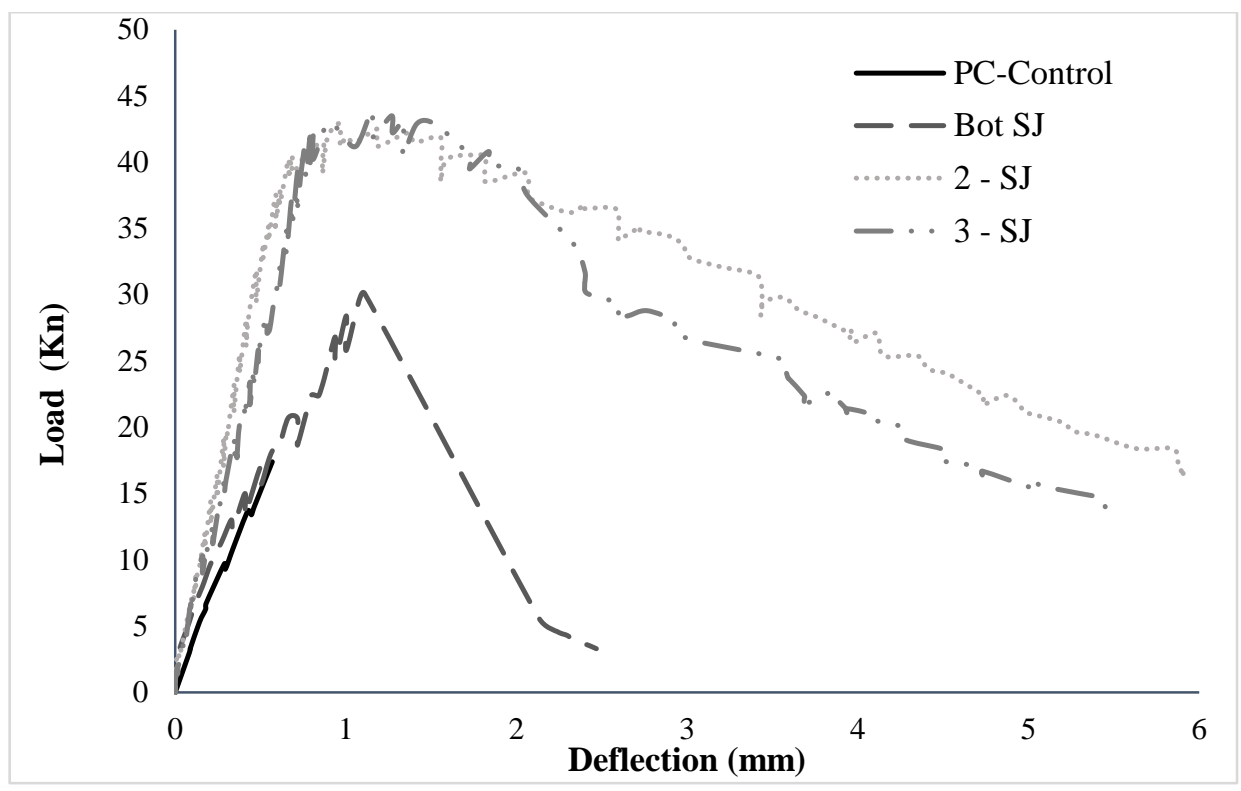

Figure 3: Load-deflection behaviour of tested beams

Table 3: Load-deflection properties of tested beams

\begin{tabular}{ccccc}
\hline Specimen & $\begin{array}{c}\text { Displacement at } \\
\text { Peak Load }(\mathrm{KN})\end{array}$ & $\begin{array}{c}\text { Residual } \\
\text { Displacement }(\mathrm{mm})\end{array}$ & Peak Load (KN) & $\begin{array}{c}\text { Moment Capacity } \\
\text { Enhancement }(\%)\end{array}$ \\
\hline$P C-$ Control & 0.57 & Broken & 17.4 & - \\
$P C-$ BOT SJ & 1.11 & 2.34 & 30.1 & 73 \\
$P C-2$ SJ & 0.96 & 5.07 & 42 & 142 \\
$P C-3$ SJ & 1.27 & 4.68 & 44 & 153 \\
\hline
\end{tabular}

\section{FINITE ELEMENT MODELLING}

The behaviour of the beams specimens under flexure were simulated and modelled using the FEA package ABAQUS for better understanding of the behaviour of such beams. An in-built model in ABAQUS known as the Concrete Damage Plasticity model developed by [9] extended by [10] is used to model both concrete and HPFRC materials. This model utilizes the material test results (compressive and tensile behaviours test) obtained by experiment which was fed into it as input data.

Similarly, ABAQUS built-in elements were used to simulate the various components of the beam specimens. These includes a 3-D stress 8-nodded linear brick element [11] used to model both concrete and HPFRC components as shown in Figure 4 and a 3-D 2-nodded truss element used to model the reinforcing bars and stirrups. A perfect bond is assumed to exist between the concrete and the HPFRC jacketing as such the interface between the two materials was modelled using the "Tie constraint" property [12].

The load-displacement results of the finite element model were plotted and compared with that of the experiment for each specimen as shown in Figure 5(a-d). Comparison of experimental and finite element model (FEM) load deflection behaviour shows that the FEM captures both load increase and stiffness of $P C-$ Control and $P C-B O T S J$ with high precision as shown in Figure 5 (a) and (b), respectively. In the case of $P C-2 S J$ and $P C-3 S J$, it was observed that the FEM was able to predict the elastic or linear behaviour of the beams with good accuracy, however the FEM was not able to accurately capture the softening behaviour after cracking of the beams as shown in Figure 5 (c) and (d), respectively. This is because plain concrete beams are more sensitive to steel fibre orientation and concentration across crack propagation paths since they lack steel reinforcing bars. However, this effect is less taken into account by the FEM as it works based on stress-strain results of small HPFRC specimens whose steel fibre orientation and concentration might be different from that of the beam specimens.

\section{ANALYTICAL MODELLING}

The beam specimens were also analysed using an analytical model by utilizing the internal stress-strain distribution of their cross section. The model was developed to predict the ultimate or moment capacity of the beams based on material test results as input data and some certain assumption made based on the beams bending theory. Material laws for each material in both tension and compression were developed resembling the material test behaviours. These material laws were used to define the stress strain distribution on the model as shown in Figures 6 and 7. 


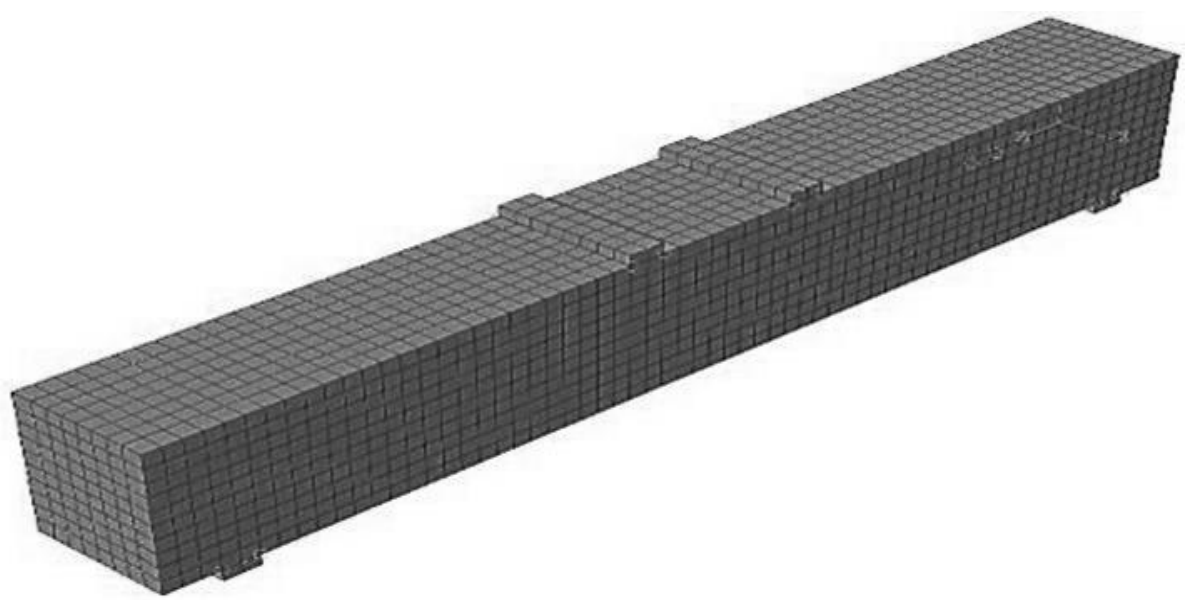

Figure 4: Meshed beam specimen showing concrete and HPFRC elements

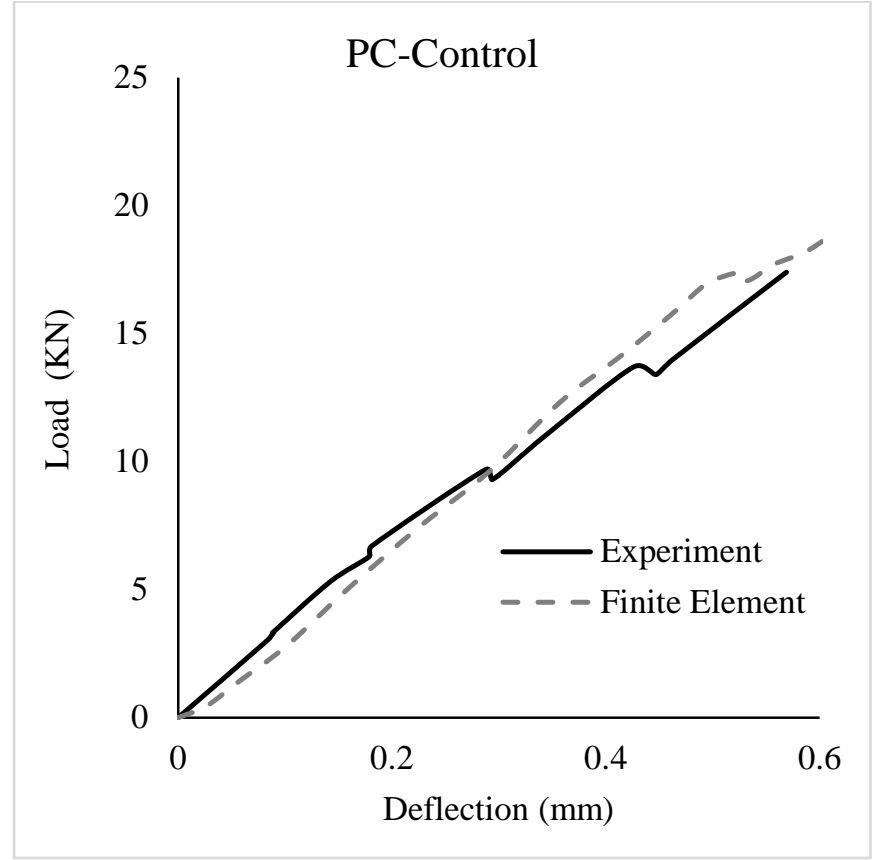

(a)

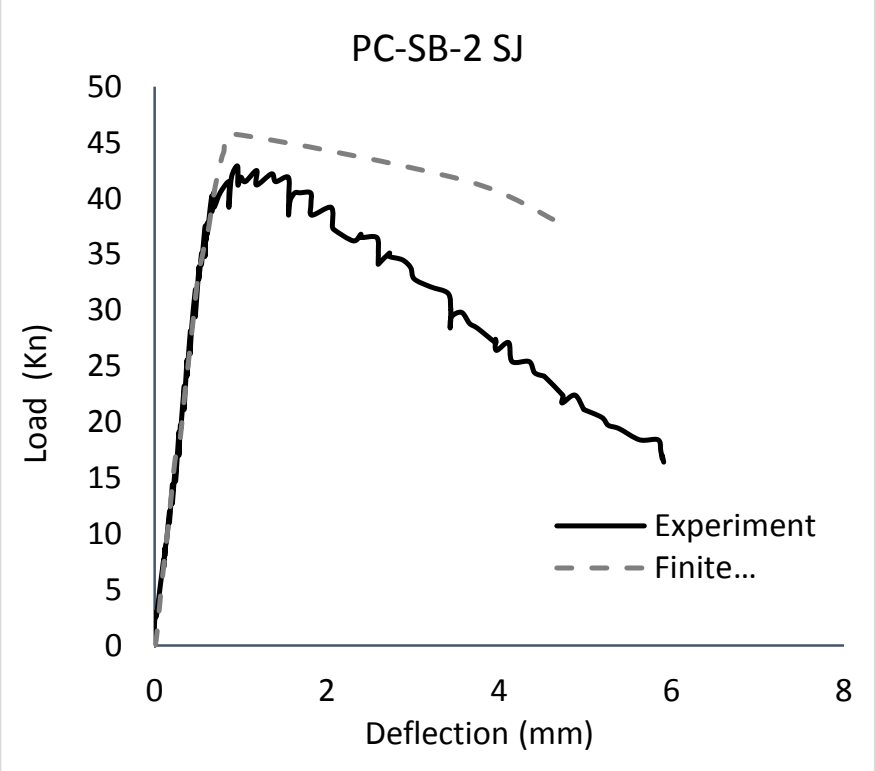

(c)

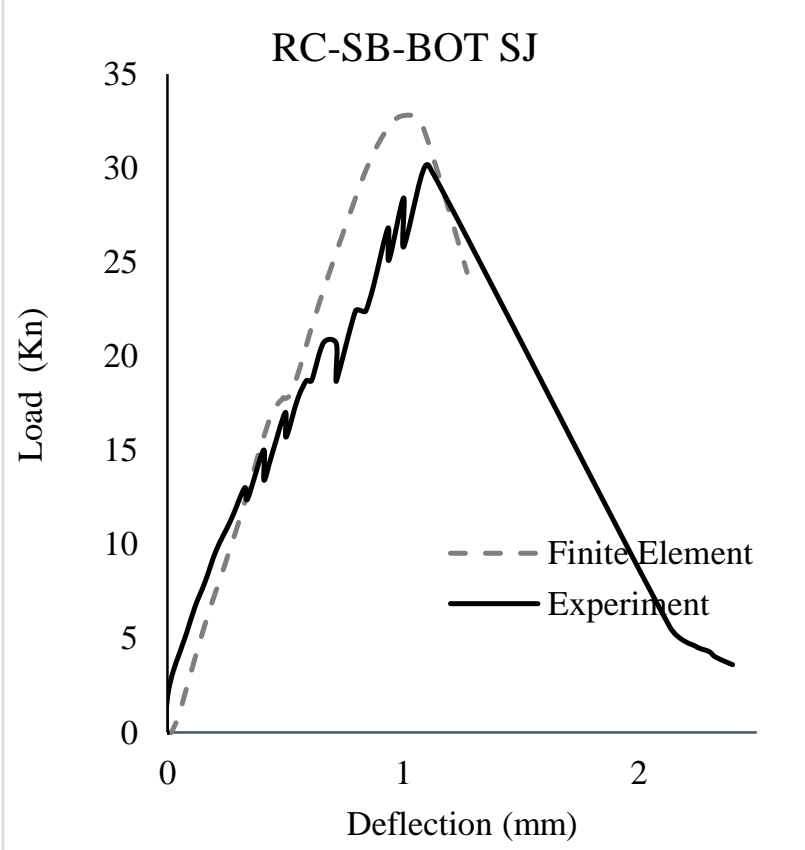

(b)

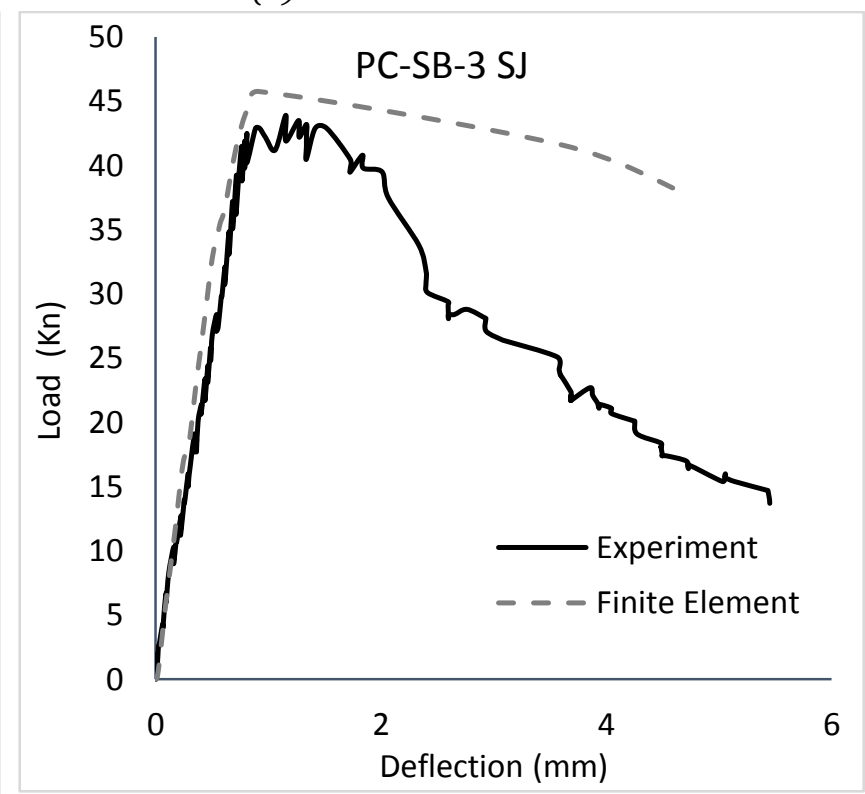

(d)

Figure 5: Load-deflection behaviour (a) PC - Control (b) PC - BOT SJ (c) PC - 2SJ (d) PC - 3 SJ 


\subsection{Abbreviations}

$\varepsilon_{c}=$ Strain in the uppermost compressive layer of the beam

$\varepsilon_{u t}=$ Strain at the bottom tensile layer of the beam $\varepsilon_{c t, \text { crack }}=$ Cracking strain of concrete in tension $\varepsilon_{\text {ut }, \text { rupture }}=$ Ultimate cracking strain of concrete in tension

$\varepsilon_{u t, \text { crack }}=$ Cracking strain of HPFRC in tension $b_{c}=$ Width of concrete beam

$b_{u}=$ Overall width of sides (longitudinal) HPFRC jackets

$b_{u, b}=$ Width of bottom HPFRC jacket

$f_{c t}=$ Cracking stress of concrete

$f_{u t}=$ Cracking stress of HPFRC

$f_{u t, n}=$ Tensile strength of HPFRC corresponding to a strain $\varepsilon_{u t, n}$

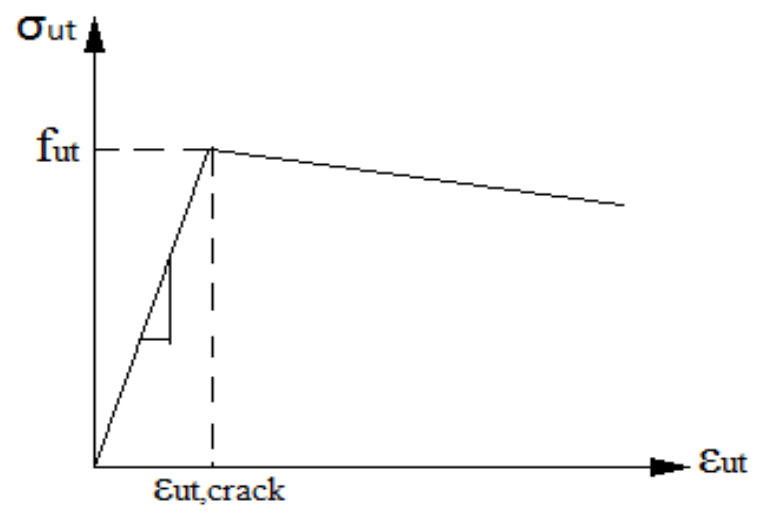

(a) $h_{c}=$ Height of concrete beam

$h_{u}=$ Height of HPFRC bottom jacket

$x=$ Neutral axis position

$y=$ Deth of concrete cracking strain for neutral axis on strain distribution diagram

$w=$ Deth of HPFRC cracking strain for neutral axis on strain distribution diagram

$w=$ Deth of conrete ultimate strain for neutral axis on strain distribution diagram

$C_{c}=$ Compressive force in concrete

$C_{u}=$ Compressive force in HPFRC

$E_{c}=$ Modulus of elasticity of concrete

$E_{u}=$ Modulus of elaticity of HPFRC

$T_{c}=$ Tensile force in concrete

$T_{u}=$ Tensile force in HPFRC

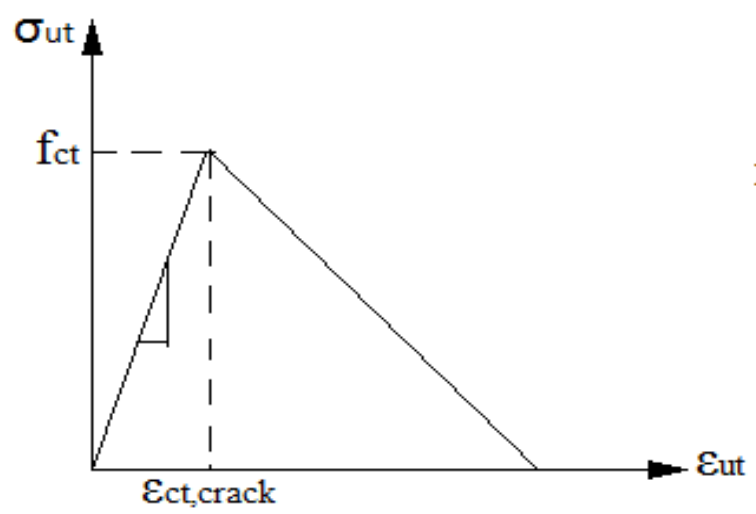

(b)

Figure 6: Material laws (a) UHPFRC tensile behaviour (b) concrete tensile behaviour
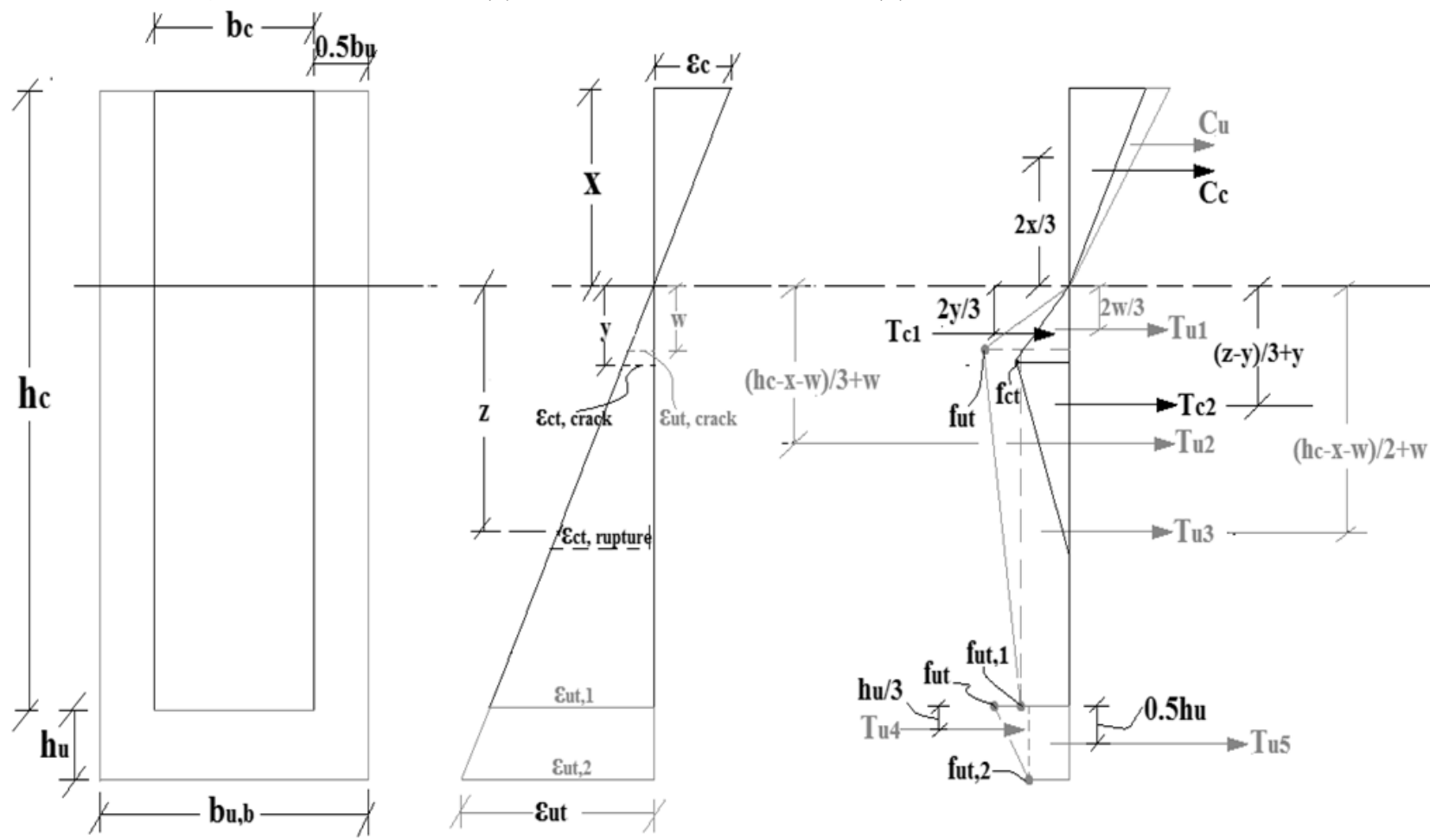

Figure 7: Analytical model definition 
The following assumptions were made in addition to the assumptions of bending theory of beams,

1) Beam specimens show monolithic behaviour, that is perfect bond exist between concrete and HPFRC

2) Material behaviours are dictated by the material laws

3) Linear strain distribution exist through the beam cross section

4) Tensile strength of concrete is not considered

5) Deformations are small.

6) Shear deformations are neglected

For a given tensile strain at the bottom of the beam $\varepsilon_{u t}$ as shown in Figure 7 , the remaining strain, stress are deduced from the uniaxial tensile strength test curves. While others are computed in terms of the neutral axis position $\mathrm{x}$ as given in equations (1) - (5).

Using Similar triangles

$$
\begin{array}{r}
\varepsilon_{c}=\frac{\varepsilon_{u t, 2} \times x}{\left(h_{c}-x+h_{u}\right)} \\
w=\frac{\varepsilon_{u t, \text { crack }} \times\left(h_{c}-x+h_{u}\right)}{\varepsilon_{u t, 2}} \\
y=\frac{\varepsilon_{c t, \text { crack }} \times\left(h_{c}-x+h_{u}\right)}{\varepsilon_{u t, 2}} \\
z=\frac{\varepsilon_{u t, 2} \times\left(h_{c}-x\right)}{\left(h_{c}-x+h_{u}\right)} \\
\varepsilon_{u t, 1}=\frac{\varepsilon_{u p t u r e} \times\left(h_{c}-x+h_{u}\right)}{\varepsilon_{u t, 2}}
\end{array}
$$

Internal forces are expressed as the product of stress and the cross-sectional area covered by the stresses as shown in equations (6) - (14)

$$
\begin{array}{r}
C_{c}=\frac{1}{2} b_{c} x\left(\varepsilon_{c} E_{c}\right) \\
C_{u}=\frac{1}{2} b_{u} x\left(\varepsilon_{c} E_{u}\right) \\
T_{c 1}=\frac{1}{2} b_{c} y f_{c t} \\
T_{c 2}=\frac{1}{2} b_{c}(z-y) f_{c t} \\
T_{u 1}=\frac{1}{2} b_{u} w f_{u t} \\
T_{u 2}=\frac{1}{2} b_{u}(h-x-w) \times\left(f_{u t}-f_{u t, 1}\right) \\
T_{u 3}=b_{u}(h-x-w) f_{u t, 1} \\
T_{u 4}=\frac{1}{2} b_{u, b} h_{u} \times\left(f_{u t}-f_{u t, 2}\right) \\
T_{u 5}=b_{u, b} h_{u} f_{u t, 2}
\end{array}
$$

The forces given in equations (6) - (14) are simplified and expressed in terms of the neutral axis depth $\mathrm{x}$. The value of $x$ at failure is obtained by iteration until equilibrium of forces is attained

$$
\begin{aligned}
\sum \text { Forces }=\left(C_{c}\right. & \left.+C_{u}\right) \\
& -\left(T_{c 1}+T_{c 2}+T_{u 1}+T_{u 3}+T_{u 4}\right. \\
& \left.+T_{u 5}\right)=0
\end{aligned}
$$

The predicted flexural moment capacity is computed by taking moment of forces about the neutral axis location

$$
\begin{aligned}
M_{\text {pred }}=C_{c} \times\left(\frac{2}{3} x\right) & +C_{u}\left(\frac{2}{3} x\right)+T_{c 1}\left(\frac{2}{3} y\right) \\
& +T_{c 2}\left(\frac{1}{3}(z-y)+y\right)+T_{c 1}\left(\frac{2}{3} w\right) \\
& +T_{u 2}\left(\frac{1}{3}\left(h_{c}-x-w\right)+w\right) \\
& +T_{u 3}\left(\frac{1}{2}\left(h_{c}-x-w\right)\right) \\
& +T_{u 4}\left(h_{c}-x+\frac{1}{3} h_{u}\right) \\
& +T_{u 5}\left(h_{c}-x+\frac{1}{2} h_{u}\right)
\end{aligned}
$$

The procedure for computing the predicted moment capacities of the beams is as shown in Figure 8.

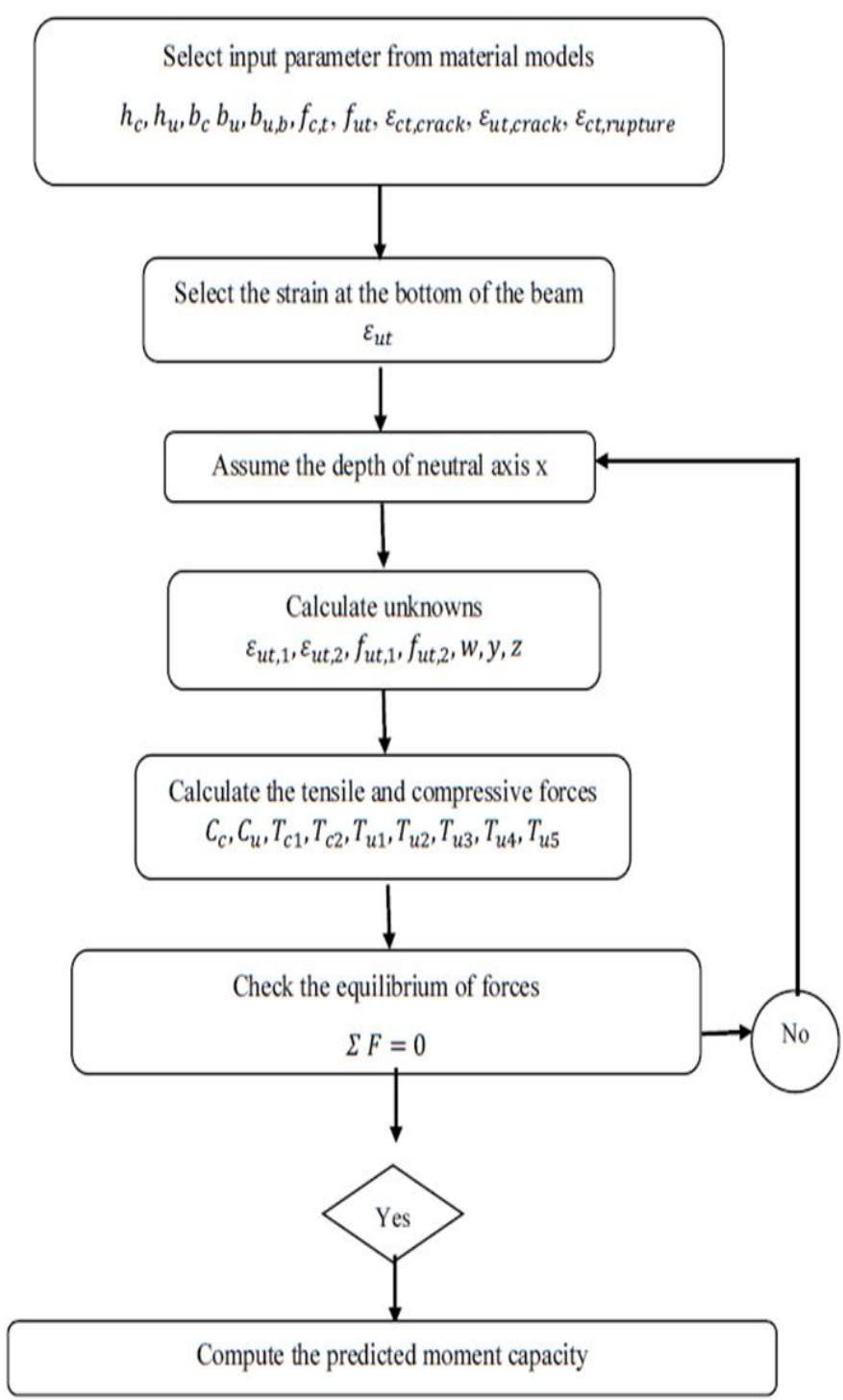

Figure 8: Analytical model flow chart 
Results of moment capacities predicted using the analytical model of the beam specimens were presented and compared with the experimental test result in Table 4. The results show good agreement.

Table 4: Analytical model results of tested beam specimens

\begin{tabular}{cccc}
\hline Specimen & $M_{\text {Exp }}$ & $M_{\text {pred }}$ & $\frac{M_{\text {Exp }}}{M_{\text {pred }}}$ ratio \\
\hline PC - & 4.9 & 5.2 & 0.942 \\
Control 1 & 8.6 & 8.9 & 0.966 \\
$P C-$ BOT SJ & 8.6 & 9.8 & 1.224 \\
$P C-2$ SJ & 12.0 & 13.6 & 0.924 \\
$P C-3$ SJ & 12.6 & & \\
\hline
\end{tabular}

\section{CONCLUSIONS}

From the study conducted, the following conclusions are drawn

1) Strengthening with HPFRC increases the cracking load, load carrying capacity and stiffness of plain concrete beams.

2) Beams strengthened at the bottom sides show brittle failure similar to that of the control as such this strengthening pattern is not recommended.

3) Beams strengthened at the longitudinal sides and at the three sides shows more ductile behaviour as the steel fibres in the sides' jacket increases the beams resistance to crack propagation giving the beams a more softening behaviour after reaching the ultimate load.

4) The strengthened beams show monolithic behaviour that is no debonding was observed.

5) The finite element was able to capture the behaviour of the strengthened beams with reasonable accuracy.

6) The analytical model is also able to predict the moment capacity of the strengthened beams specimens.

\section{REFERENCES}

[1] Hussein, L., Amleh, L. "Structural Behaviour of UltraHigh Performance Fibre Reinforced ConcreteNormal Strength Concrete or High Strength Concrete Composite Members", Construction and Building Materials, vol. 93, 2015, pp. 1105 - 1116.

[2] Habel, K., Denarié, E., \& Bruhwiler, E. "Experimental Investigation of Composite Ultra-High Performance Fibre-Reinforced Concrete and Conventional
Concrete Members", ACI Structural Journal, vol.104, 2007, pp. 10-20

[3] Martinola, G., Meda, A., Plizzari, G. A., and Rinaldi, Z. "Strengthening and Repair of RC Beams with Fibre Reinforced Concrete", Cement Concrete Compos., vol. 32, 2010, pp.731-9.

[4] Prem, P. R., Murthy, A. R., Ramesh, G., Bharatkumar, B. H., and Iyer, N. R. "Flexural Behaviour of Damaged RC Beams Strengthened with Ultra-High Performance Concrete", Advances in Structural Engineering, vol. 3, 2015, pp. 2057 - 2069.

[5] Lampropoulos, A. P., Paschalis, S. A., Tsioulou, O. T., and Dritsos, S. E. "Strengthening of Reinforced Concrete Beams using Ultra-High Performance Fibre Reinforced Concrete (UHPFRC)", Engineering Structures, vol. 106, 2016, pp. 370 - 384.

[6] Alaee, F. J., and Karihaloo BL. (2003), "Retrofitting of Reinforced Concrete Beams with CARDIFRC", Journal of Composites for Construction, vol. 7, 2003, pp. 174.

[7] Noshiravani, T., and Brühwiler, E. "Experimental Investigation on Reinforced Ultra-High Performance Fibre-Reinforced Concrete Composite Beams Subjected to Combined Bending and Shear", ACI Structural Journal, vol. 110, 2013, pp. 251 - 262.

[8] Mohammed, T., Abu Bakar, B. H., and Bunnori, N. M. "Torsional Improvement of Reinforced Concrete Beams using Ultra High-Performance Fibre Reinforced Concrete (UHPFC) Jackets Experimental Study", Construction and Building Materials, vol. 106, 2016, pp. 533-542.

[9] Lubliner, J., Oliver, J., Oller, S., and Onate, E. "A Plastic-Damage Model for Concrete", International Journal of Solids and Structures, vol. 25, 1989, pp. 299-326.

[10] Jankowiak, I. "Analysis of RC Beams Strengthened by CFRP Strips - Experimental and FEA Study", Archives of Civil and Mechanical Engineering, vol. 12, 2012, pp. 376 - 388

[11] Lee, J. and Fenves, G.L. "Plastic-Damage Model for Cyclic Loading of Concrete Structures", Journal of Engineering Mechanics, ASCE, vol. 124, 1998, pp. 892-900.

[12] Chalioris, C. E., Thermou, G. E., and Pantazopoulou, S. J. "Behaviour of Rehabilitated RC Beams with Self-Compacting Concrete JacketingAnalytical and Test Results", Construction and Building Materials, vol. 55, 2014, pp. 257-273. 